\title{
DESENVOLVIMENTO DE OBJETOS DE APRENDIZAGEM NAS ÁREAS DE LÍNGUA PORTUGUESA E MATEMÁTICA ${ }^{1}$
}

\author{
Carmen Vieira Mathias - (UNIFRA)- (carmen@unifra.br) \\ Clandio Timm Maques - (UNIFRA) - (clandio@unifra.br) \\ Daiana Siqueira - (UNIFRA) - (daia_mi@yahoo.com.br) \\ Janette Mariano Godois -(UNIFRA)- (jmgletras@yahoo.com.br) \\ Larissa Rosa dos Santos - (UNIFRA)- (lari.matemática@yahoo.com.br) \\ Marta Lia Genro Appel -(UNIFRA)- (mlia@ terra.com.br) \\ Rosane Mesquita Cavallin -(UNIFRA)- (rosane_mesquitacn@yahoo.com.br) \\ Solange Binotto Fagan -(UNIFRA)- (sfagan@unifra.br)
}

\section{Resumo}

Este artigo tem por objetivo apresentar as experiências obtidas por docentes e discentes da UNIFRA na produção de objetos de aprendizagem desenvolvidos segundo a metodologia RIVED (Rede Interativa Virtual de Educação) nas áreas de Língua Portuguesa e Matemática para aplicação no Ensino Básico. De forma especifica, apresentaremos os resultados referentes aos objetos: "O plural dos substantivos compostos separados por hífen" referente a área de língua portuguesa e "Análise combinatória" referente a área de matemática desenvolvidos pelo grupo RIVED/UNIFRA.

Palavras-chaves: Objeto de Aprendizagem, Interatividade, educação

\begin{abstract}
In this work we present the experience obtained of students and teachers from the UNIFRA University on the production of Learning Objects using the RIVED/MEC (Virtual Interactive Network of Education) methodology in themes on Portuguese and Mathematic that would be applied on the Secondary School. In a specific way, we present the results of the objects: "The plural of the composed substantives with hyphen" from the Portuguese area and "Combinatory analysis" from the mathematic science that are developed from the RIVED/UNIFRA group.
\end{abstract}

Keywords: learning objects, interactivity, education

\footnotetext{
${ }^{1}$ Projeto financiado pela SEED/ MEC, convênio UFSM - UNIFRA
} 


\section{INTRODUÇÃO}

Com o fácil acesso aos computadores e a Internet, foi aberta uma nova dimensão para a introdução de novas tecnologias no processo ensino-aprendizagem, principalmente no que diz respeito a softwares e atividades que possibilitem um alto grau de interatividade por parte dos aprendizes. Isto traz uma série de vantagens, como, por exemplo, facilitar o esclarecimento de dúvidas e diminuir o isolamento dos alunos com vistas a favorecer a obtenção de informações sobre seu aproveitamento, motivando o aprendizado do mesmo.

Várias pesquisas vêm sendo desenvolvidas no sentido de mostrar a viabilidade e a eficácia do uso dessas atividades no processo ensino-aprendizagem. Nesse sentido destaca-se o artigo de MONTEIRO et al (2006), que apresenta a teoria da aprendizagem significativa como suporte teórico além de relatar um estudo de caso com um objeto de aprendizagem exemplificando a funcionalidade desta ferramenta pedagógica.

A Secretaria de Educação à Distância do Ministério da Educação através do RIVED tem buscado oportunizar aos estudantes universitários do Brasil a construção de objetos de aprendizagem, visando a melhoria do processo de ensino e aprendizagem em diferentes áreas de conhecimento da educação básica. Segundo Nascimento (2004) entende-se por Objeto de Aprendizagem:

[...] qualquer recurso que possa ser reutilizado para dar suporte ao aprendizado. Sua principal idéia é 'quebrar' o conteúdo educacional disciplinar em pequenos trechos que podem ser reutilizados em vários ambientes de aprendizagem. Qualquer material eletrônico que provém informações para a construção de conhecimento pode ser considerado um objeto de aprendizagem, seja essa informação em forma de uma imagem, uma página HTM, uma animação ou simulação.

Os Objetos de Aprendizagem tem se mostrado uma alternativa pedagógica eficaz no ensino de conteúdos de disciplinas da Educação Básica. Essas atividades, no momento em que são realizadas em sala de aula, ou fora dela, fazem com que o aluno se questione e busque respostas às suas dúvidas, descobrindo um caminho diferente do que está acostumado e obtendo acesso às respostas a partir das indagações por ele levantadas. Nesse sentido, segundo SILVEIRA et al (2006) a utilização desses Objetos pelos professores do Ensino Médio ou Fundamental é um ponto de partida para provocar no aluno o interesse e a necessidade de aprofundar seus conhecimentos.

Dentro desse contexto, desde 2005 o Centro Universitário Franciscano (UNIFRA) tem desenvolvido pesquisas para produção de conteúdos educacionais digitais a serem utilizados em diversas situações de aprendizagem, tanto por professores quanto por alunos. Este estudo tem dado ênfase na integração de aplicações tecnológicas no currículo e não no uso da tecnologia em si, cuja filosofia está alinhada aos princípios defendidos pelo RIVED.

$\mathrm{O}$ que pretendemos nesse artigo é fazer um relato sobre a experiência do desenvolvimento de dois Objetos de Aprendizagem, utilizando a metodologia RIVED, um na área de Matemática e outro na área de Letras, atividades estas que estão sendo desenvolvidos por equipes do grupo RIVED-UNIFRA. 


\section{METODOLOGIA}

Durante o ano de 2006, o grupo RIVED-UNIFRA, composto por quatro professores e quinze alunos de graduação e pós-graduação teve como meta a produção de oito objetos de aprendizagem, nas áreas de Física, Química e Matemática. Para fazêlo alguns membros do grupo, participaram do curso de capacitação, oferecido através da plataforma e-proinfo, um ambiente de aprendizagem virtual gratuito desenvolvido pelo Departamento de Educação a Distância do Ministério da Educação do Brasil, que segundo NASCIMENTO (2005), visou atingir dois propósitos: desenvolver recursos digitais para o RIVED e enriquecer o repertório dos docentes das universidades e futuros professores do Ensino Básico, na criação de material digital de aprendizagem.

Atualmente, a UNIFRA em convênio com a UFSM (Universidade Federal de Santa Maria) se soma às demais 21 Instituições de Ensino Superior que, estão participando da construção de diversos objetos de aprendizagem. O grupo RIVEDUNIFRA, conta com a atuação de vinte e seis professores, de diferentes áreas do conhecimento e de cinqüenta e oito bolsistas, também oriundos de diversos cursos, incluindo Graduação e Pós-Graduação.

Primeiramente, a equipe que fez a capacitação, elaborou uma série de reuniões, com o objetivo de transmitir ao grupo, as informações necessárias para entender a metodologia difundida pelo grupo RIVED/SEED/MEC para a construção de materiais didáticos digitais, isto é, os objetos de aprendizagem.

Segundo a metodologia RIVED, cada grupo de trabalho, compostos por um ou dois professores da área, dois alunos de graduação do curso específico, e um aluno do curso de sistemas de informação (e no nosso caso, um aluno do curso de design e um aluno da área de comunicação), deve inicialmente buscar um tema de interesse no qual é possível desenvolver uma atividade multimídia que contemple os objetivos do RIVED.

Em seguida, na primeira etapa da metodologia temos o desenvolvimento do designer pedagógico, no qual se define os objetivos das atividades, respondendo a uma série de perguntas, tais como: Como o aluno para o qual você está planejando esta atividade encontraria de interessante e inovador na mesma? Quais aplicações e/ou exemplos do mundo real podem ser utilizados para engajar os alunos? O que pode ser interativo na atividade? Qual o público alvo? Como o conteúdo será apresentado? Quando e como o objeto será usado?, entre outras.

$\mathrm{Na}$ segunda etapa, que se denomina roteiro pedagógico, faz-se o detalhamento de como este tema deverá ser abordado na atividade, utilizando imagens, idéias e anotando todas as informações importantes para ele ser construído e programado. Nessa fase do desenvolvimento é muito importante o atendimento por parte de um roteirista, um design e um de técnico da área de informática, pois eles fazem uma análise detalhada da viabilidade do ambiente de desenvolvimento que será adotado. Percebe-se que essa fase do desenvolvimento do projeto é fundamental, pois essa interação será significativa para a fase seguinte, chamada de produção, na qual o grupo de técnicos produz o Objeto de Aprendizagem sob constante consulta ao grupo pedagógico e às informações descritas no design pedagógico, e principalmente no roteiro. Para a produção dos Objetos de Aprendizagem o software mais utilizado é o Macromedia Flash.

Enquanto a fase de produção é realizada pela parte técnica, a equipe pedagógica elabora o Guia do Professor, que é de fundamental importância na fase de distribuição e implementação do Objeto. Esse guia, segundo REIS e FARIA (2003), procura fazer o encadeamento das atividades de acordo com os objetivos propostos no Design Pedagógico, buscando ajudar o professor com sugestões de ações a serem tomadas no 
decorrer do trabalho. Nele são sugeridas outras atividades que podem acontecer com ou sem o uso do computador para àquele determinado tema.

Por fim, deve-se aplicar o Objeto a fim de avaliar a real correspondência entre o objetivo proposto e o entendimento do mesmo, por parte do publico alvo: os alunos.

\section{DESENVOLVIMENTO DOS TRABALHOS}

O grupo RIVED-UNIFRA, é composto por professores e alunos nas áreas de Biologia, Ciências, Filosofia, Física, Geografia, História, Língua Portuguesa, Literatura Brasileira, Química, Matemática, Ciência da Computação, Sistemas de Informação, Design e Comunicação.

Cada professor (ou dupla de professores) orienta um ou dois alunos da área especifica, sendo estes responsáveis pela confecção do design pedagógico e do roteiro de cada Objeto, com encontros semanais, sempre com o acompanhamento de um ou dois alunos das áreas da informática, design e comunicação. $\mathrm{O}$ atendimento dos alunos das outras áreas é necessário para o entrosamento das equipes pedagógicas e técnica, além de ser extremamente importante na realização dos objetivos propostos por cada equipe.

A seguir, pretende-se relatar a experiência sobre o desenvolvimento de dois Objetos de Aprendizagem, utilizando a metodologia do RIVED, que estão sendo desenvolvidos pelo grupo RIVED-UNIFRA.

Segundo um cronograma previamente determinado pela coordenação do projeto, foi fixado metas para a produção dos Objetos de Aprendizagem, para melhor orientar as equipes. Esse cronograma contempla as etapas descritas anteriormente. Logo após primeira etapa, ou seja, a capacitação das equipes sugeriu-se que as mesmas desenvolvessem o design pedagógico e o roteiro, para então passar para a fase de produção. Seguindo o cronograma, até o presente momento, estamos com dois objetos na fase final de produção que estão sendo implementados pela equipe da informática, cinco na fase inicial de produção, isto é, a equipe de designers está criando os desenhos definidos pela equipe pedagógica e roteiristas, quatro na finalização do roteiro, quatro na fase de adaptação do roteiro e os demais na fase do design pedagógico.

Os Objetos que se encontram na fase final de produção são os de Letras e Matemática. Objetos esses que são foco de nosso relato.

\section{Elaboração e do Objeto de Língua Portuguesa}

A equipe do Curso de Letras é liderada por uma única professora que orienta quatro alunas bolsistas e uma voluntária, envolvidas ativamente na produção de três Objetos. Um destes objetos, o qual é destinado a desenvolver o tema Plural dos substantivos compostos separados por hífen, está na última etapa de produção.

Este Objeto de Aprendizagem será aplicado a alunos do sétimo e oitavo ano do Ensino Fundamental e tem como objetivo auxiliar a prática do professor, ao trabalhar o conteúdo referido, e conseguir lançar mão de recursos virtuais que possam facilitar o trabalho docente, bem como inserir o aluno do Ensino Fundamental no universo virtual.

A metodologia de trabalho nesse grupo tem seguido as seguintes etapas: primeiramente a escolha dos temas e, posterior a isto o estudo dos mesmos (pesquisa bibliográfica). Realizada a tarefa já esboçada partimos para a montagem dos referidos objetos. Os encontros de pesquisa e o estudo nesta fase foram muito intensos. As reuniões ocorreram duas tardes da semana (mês de março de 2007/segunda quinzena e durante o mês de abril). A partir de então fomos, aos poucos, nos engajando aos demais 
colaboradores: bolsistas do Designer, da Comunicação e da Informática. Para RÖSING (2005) o mergulho do aluno nos oceanos da internet, da rede interativa e da multimídia estão em todo ambiente, que ultrapassam inclusive o âmbito escolar, o que reforça a necessidade do educador em buscar sua própria inserção no referido universo, para que melhor atue em sala de aula.

É importante ressaltar a vinda da professora Anna Cristina de Azevedo Nascimento da SEED/MEC para um curso de capacitação e de supervisão dos objetos em construção, na UNIFRA, em abril do corrente ano.

As etapas que estão em construção se destinam à implementação das telas e à elaboração do Guia do Professor, que é um ícone do Objeto que se destina ao professor usuário, com as devidas explicações sobre o funcionamento do recurso didático virtual, por ele utilizado.

A seguir, apresentamos algumas telas desse objeto, ainda em fase de conclusão.

A Figura 1 é a tela de abertura do Objeto. Essa atividade será conduzida na forma de um jogo e o aluno escolhe qual ambiente quer entrar (casa, rua, praia, floresta ou feira), somando pontos conforme o emprego correto do plural do substantivo.

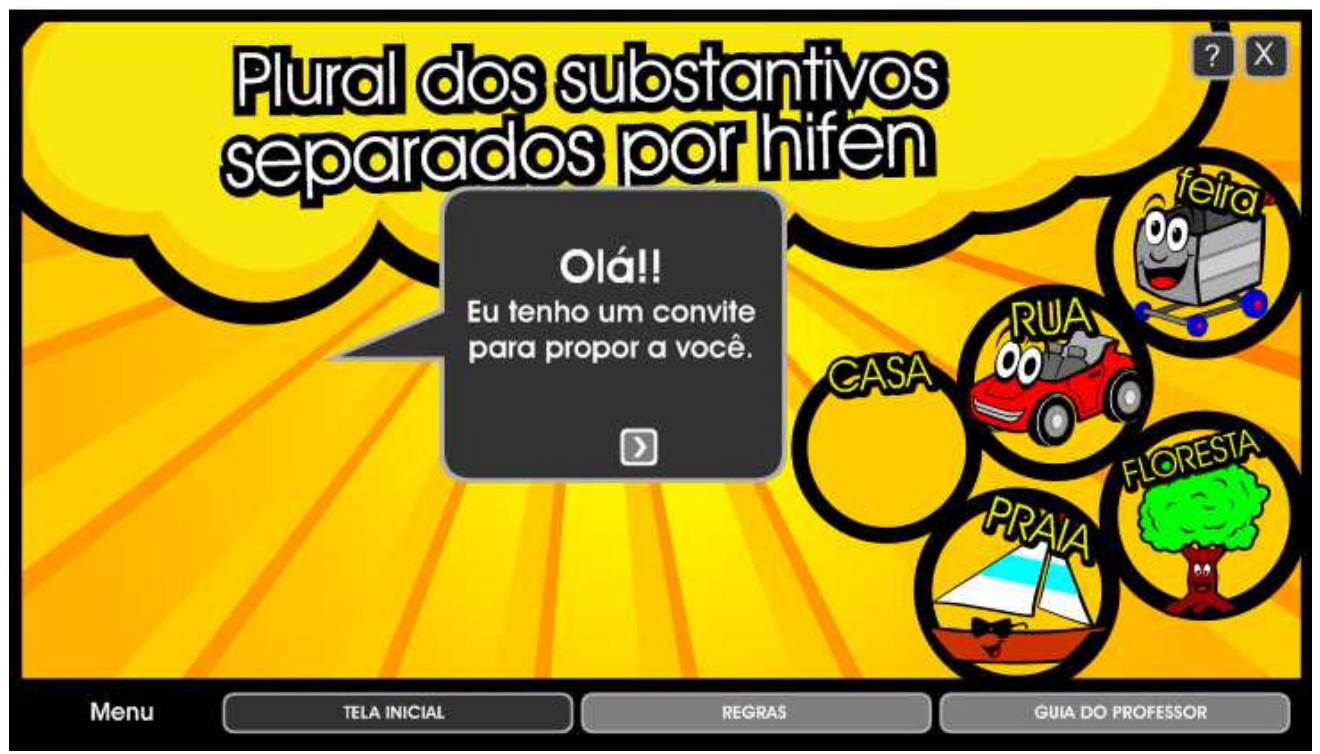

Figura 1 - Tela inicial do objeto de língua portuguesa.

A Figura 2 representa o ambiente da praia, que aparece quando o aluno "clica" na tela inicial no ícone praia. Percebe-se que nesse ambiente aparecem vários objetos cujos nomes são substantivos compostos e o aluno, através de um agente pedagógico irá participar das atividades expostas. O mesmo ocorre nas demais telas, que já estão prontas e sendo implementadas pela equipe de Informática. 


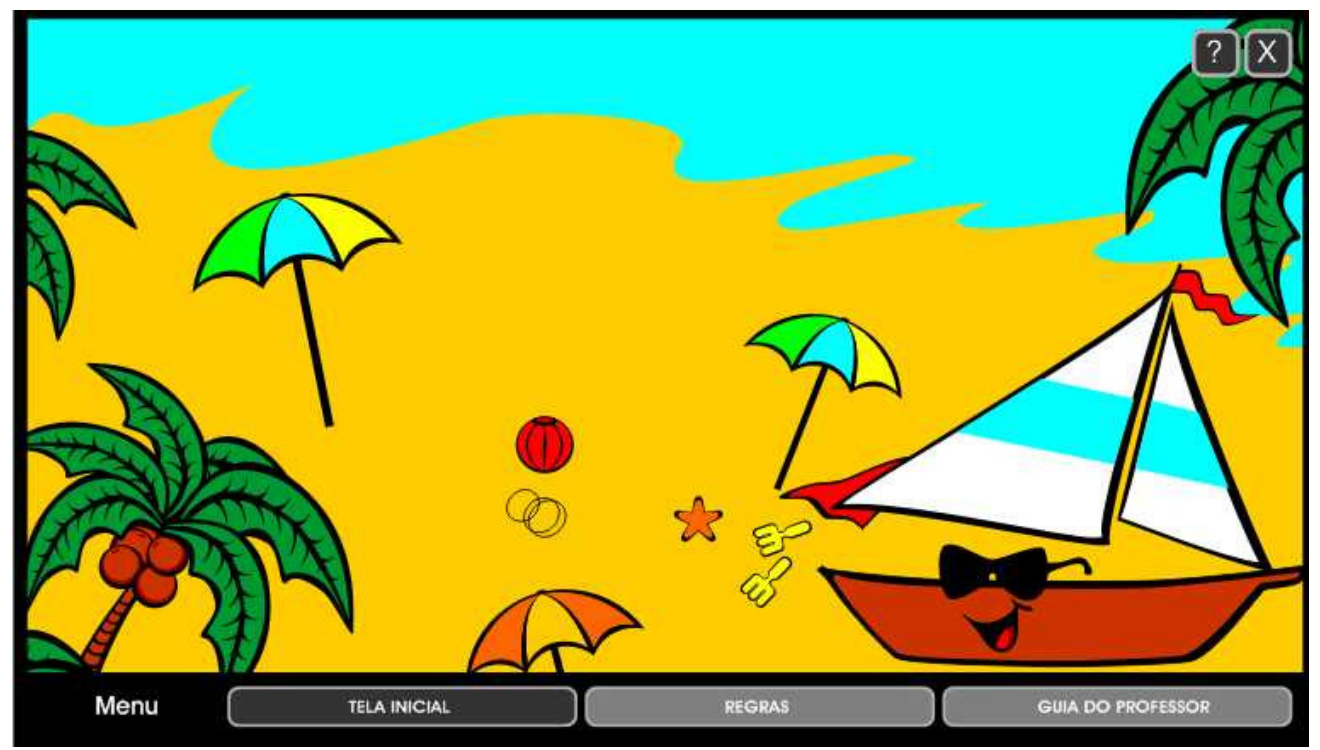

Figura 2 - Tela de escolhas de atividades no objeto de língua portuguesa

\section{Elaboração do Objeto de Matemática}

A equipe da Matemática, que é formada por dois professores e dois acadêmicos do curso de licenciatura, desenvolveu uma atividade que versa sob o tema "análise combinatória", visto que esse conteúdo gera muitas dúvidas e nem sempre as questões estão absolutamente claras, o que causa muita confusão no raciocínio do aluno. O principal objetivo desta atividade é fazer com que o aluno perceba quais as diferenças existentes entre problemas de combinação, arranjo e permutação, de forma interativa e contextualizada.

$\mathrm{Na}$ tela inicial, veja Figura 3, o aluno tem como plano de fundo para as atividades, uma cidade onde ele visualiza vários ícones, que ao serem "clicados" levam para outras telas, onde de fato eles deverão resolver o problema proposto, experimentando as várias situações do cotidiano. Essa tela foi planejada para que o aluno perceba que o conteúdo que é tema do Objeto, está presente em sua vida, fazendo com que ele se sinta motivado a prosseguir com a atividade.

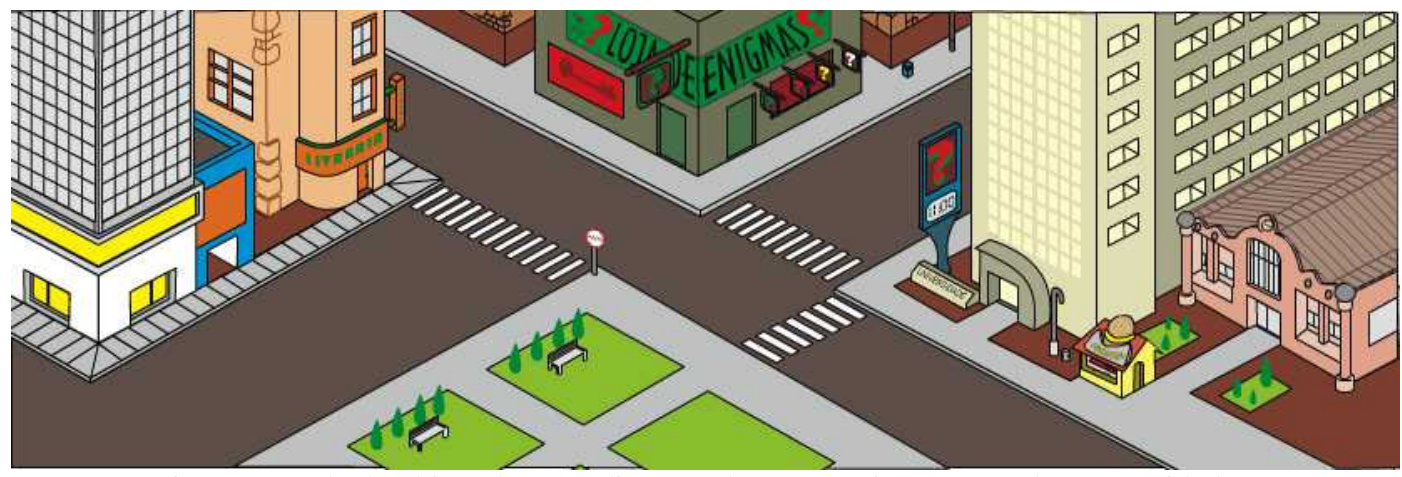

Figura 3 - Tela do objeto de aprendizagem de Matemática mostrando uma "Cidade".

A clicar em um ícone, como por exemplo, na casa lotérica, o aluno visualiza uma nova tela, veja Figura 4. 


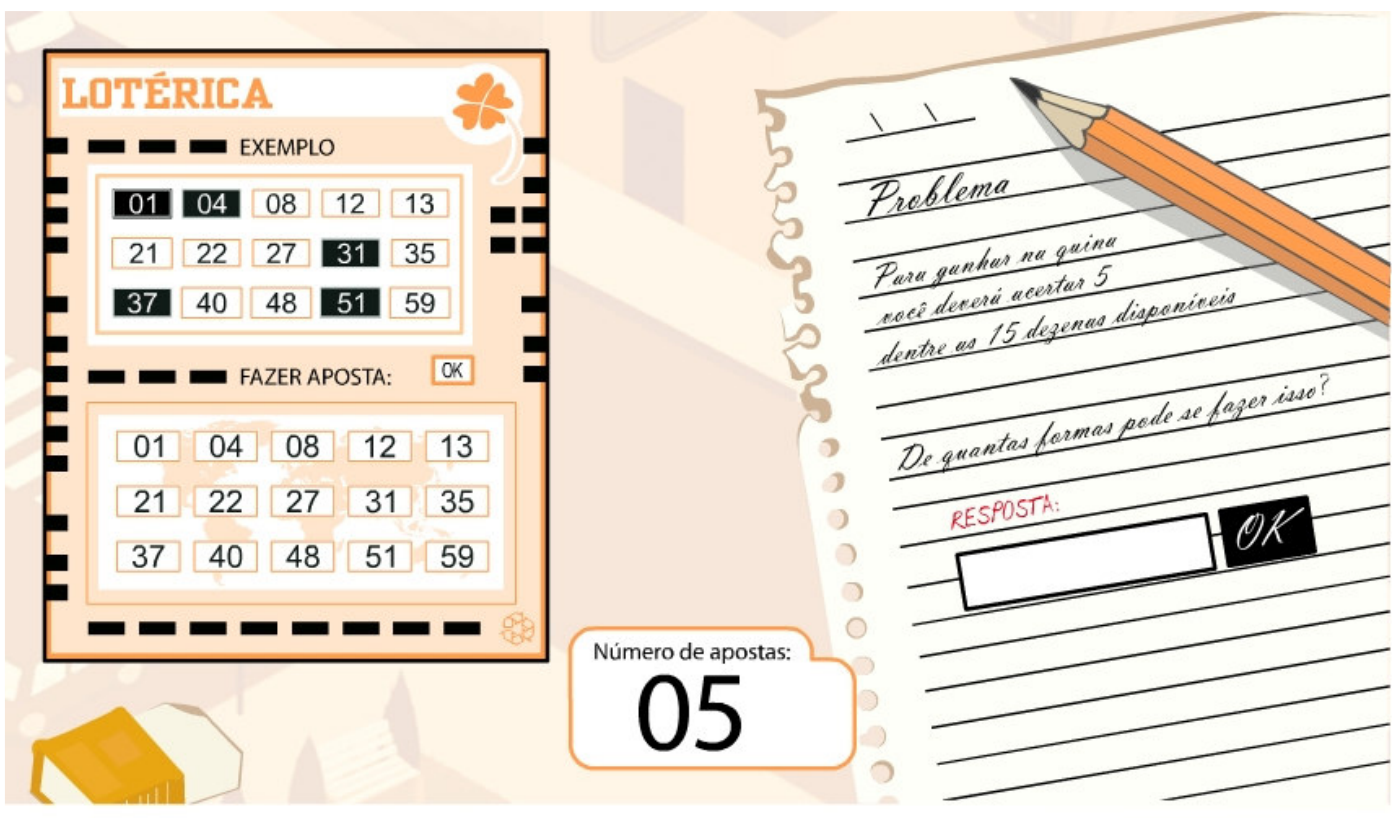

Figura 4 - Tela do objeto de aprendizagem de Matemática relatando os números em uma "Lotérica".

Nessa tela da casa lotérica o aluno deverá simular uma aposta na Quina, marcando cinco números dos quinze disponíveis, após fazê-lo o aluno aperta no botão OK. O número máximo de apostas será de cinco, ao final do experimento o aluno deverá perceber que esse é um problema onde a ordem dos elementos não importa, o que o caracteriza como um problema de combinação. Percebe-se que nessa atividade, o aluno é levado a fazer uma simulação de um jogo, que certamente ele já fez em algum momento de sua vida e que talvez não tenha percebido que esse pode ser um problema de análise combinatória.

Ao clicar no ícone do banco na tela inicial, ver Figura 3, o aluno visualizará a tela da Figura 5.

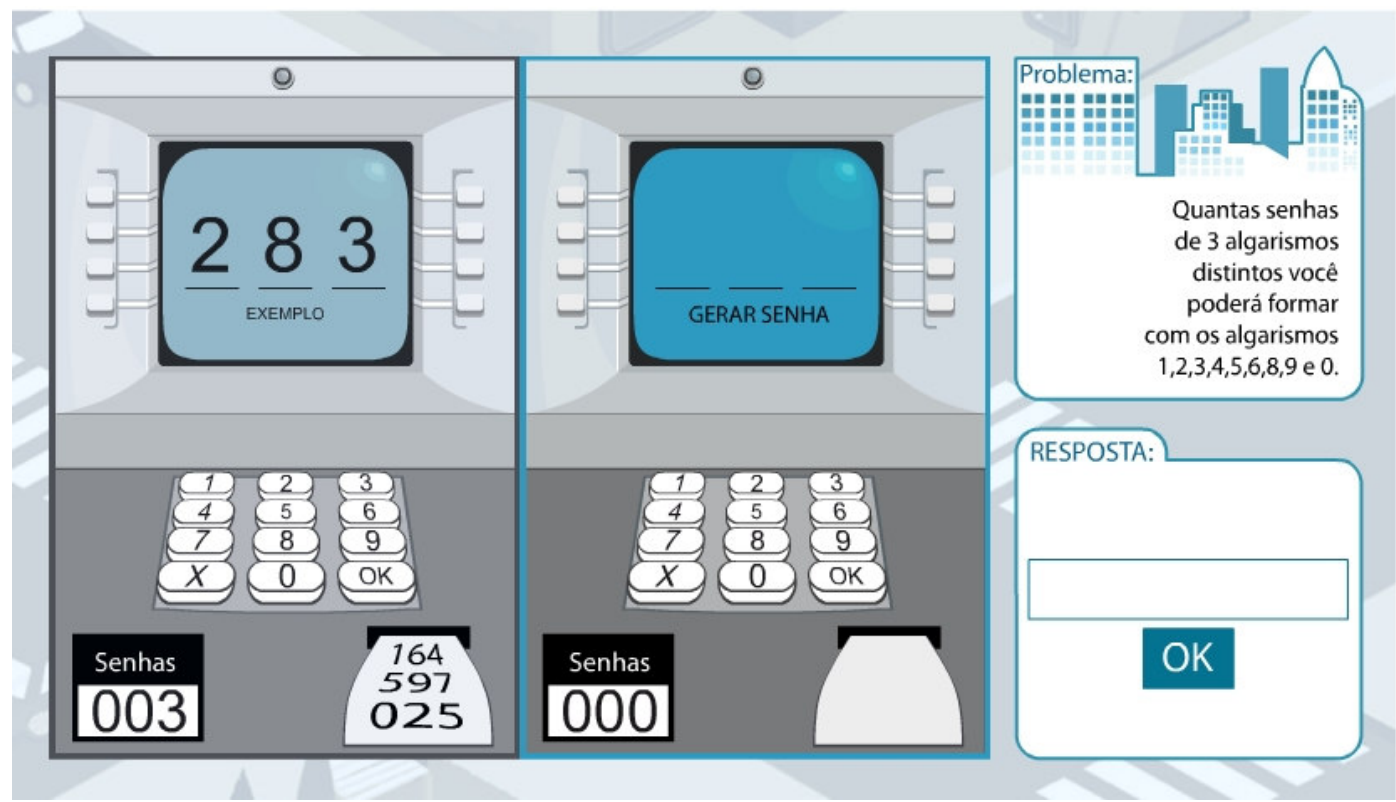

Figura 5 - Tela para um banco de senhas - Objeto de Aprendizagem de Matemática. 
Nessa etapa da atividade, o aluno deverá simular a criação de senhas para uma conta em um banco, utilizando para isso apenas uma quantidade limitada de números, no caso três, de dez algarismos disponíveis. Da mesma forma que no caso anterior, o aluno deverá gerar no máximo cinco senhas e decidir se esse é um problema de arranjo, combinação ou permutação. Esse tipo de atividade acontece em todos os ícones disponíveis na Tela 1 (Figura 3), cada um com sua respectiva tela, como por exemplo na placa do carro, na placa de pare, na livraria e no grupo de ciclistas.

Esse objeto possui um menu que está ainda em fase de criação, o qual fará uma ligação com todas as atividades disponíveis, um histórico, definições, atividades extras, telas de ajuda e uma calculadora, tudo para que o objeto seja de certa forma autosuficiente, dando ênfase na reutilização do objeto, como prevê a metodologia RIVED.

\section{DISCUSSÕES E CONCLUSÕES}

No processo de construção desses dois Objetos de Aprendizagem, ainda em fase de conclusão, mesmo com todos os encontros e diálogos possíveis entre o que chamamos de área técnica e pedagógica, ainda aconteceram algumas discussões em torno do que foi imaginado e aquilo que foi produzido. Então, estamos procurando realizar, sempre que possível, encontros com todas as equipes de trabalho, para definir de forma clara e precisa, todos os componentes do Objeto de Aprendizagem com o intuito de empregar o tempo de modo mais producente.

$\mathrm{Na}$ escolha do tema análise combinatória, buscou-se abordar um assunto que possui alta aplicabilidade na vida do aluno. Ele vem ao encontro do que preconiza a Metodologia RIVED, a importância da vivência do aluno como fator de motivação no processo de ensino-aprendizagem.

Quanto ao objeto de Língua Portuguesa (emprego do plural dos substantivos separados por hífen), pode-se inferir que a atividade servirá de recurso e grande motivador ao trabalho docente, no sentido de aproximar os interesses do aluno ao universo de aplicação dos referidos substantivos no seu cotidiano.

A próxima etapa é testar a eficácia desses Objetos junto aos alunos do Ensino Fundamental, no caso da atividade de língua portuguesa, e no Ensino Médio o Objeto de Matemática, a fim de detectar as possíveis falhas. Ele estará disponível aos usuários no site do Grupo RIVED-UNIFRA (http://sites.unifra.br/rived) o que facilitará seu acesso. A experiência adquirida na elaboração desses Objetos de Aprendizagem, segundo a metodologia do RIVED, tem auxiliado principalmente a grupo responsável pela parte técnica na construção dos demais Objetos envolvidos em nosso projeto, contribuindo para a utilização de recursos tecnológicos digitais por professores da Educação Básica.

\section{Referências bibliográficas}

FARIA C.O.; REIS C.F.; Uma Apresentação do RIVED - Rede Internacional Virtual de Educação, CIEM, Blumenau, maio 2003. Disponível em: <http://www.rived.mec.gov.br/artigos/ciaem.pdf >. Acesso em: 20 jun. 2007

MONTEIRO, B.S., CRUZ H.P., ANDRADE, M. GOUVEIA, T. TAVARES, L. ANJOS, L.F.C.; Metodologia de desenvolvimento de objetos de aprendizagem com foco na aprendizagem significativa, Disponível em: < www.rived.mec.gov.br/artigos/ 
2006_XVIISBIERomero.pdf >. Acesso em: 20 jun. 2007

NASciMento, A. C., Taking The Next Step with The Project RIVED, World Conference on Educational Multimedia, Hypermedia \& Telecommunications Lugano, Switzerland, junho 2004. Disponível em: <http://www.rived.mec.gov.br/artigos /nextstep.pdf>. Acesso em: 10 jun. 2007

NASCIMENTO, A. C., Construindo Comunidades de Elaboradores de Objetos de Aprendizagem através de Conteúdo, Tutoria e Interação dos Pares Secretaria de Educação a Distância, Ministério da Educação, dez. 2005, Disponível em: $<$ http://www.rived.mec.gov.br/artigos/Anna20063.pdf>. Acesso em: 18 jun. 2007

RÖSING, T.; RETTENMAIER, M. Questões de literatura para jovens. Passo Fundo: Ed. Universidade de Passo Fundo, 2005.

SILVEIRA ,A. M., SANTOS L. M., BARBOSA, M., BISOGNIN E., FAGAN, S. B., BISOGNIN,V. , Desenvolvimento de um Objeto de Aprendizagem sobre a Poluição Global. Revista Novas Tecnologias na Educação - CINTED - Centro Interdisciplinar de Novas Tecnologias na Educação - Vol. 4 No 2. UFRGS, 2005. 